\title{
Lithium-ion battery performance modeling based on the energy discharge level
}

\author{
Ángel Porras-Hermoso $\odot$, Santiago Pindado $\odot$ and Javier Cubas $\odot$ \\ Instituto Universitario de Microgravedad 'Ignacio Da Riva' (IDR/UPM), ETSI Aeronáutica y del Espacio, \\ Universidad Politécnica de Madrid, Pza. del Cardenal Cisneros 3, Madrid 28040, Spain \\ E-mail: santiago.pindado@upm.es (S Pindado)
}

\begin{abstract}
In the present work, a new model for Li-ion battery performance is proposed. This model is based on the energy discharge level (in relation to full capacity), and was developed after testing carried out on the battery of the UPMSat- 2 satellite. These thermal vacuum chamber tests showed extremely high energy efficiencies. The results from the proposed model reproduce the test results (discharging/charging processes) of a $17.2 \mathrm{~A} \cdot \mathrm{h}$ Li-ion battery.
\end{abstract}

Keywords: Li-ion battery, equivalent circuit model, SOC estimation, energy balance

\section{Introduction}

Different equivalent circuit models have been proposed in the past to analyze Li-ion battery performance, see for instance the works of Newman et al [1] He et al [2] Mousavi et al [3] and Fotoui et al [4]. One of the problems that arises when analyzing batteries is the performance dependence on the output/ input current (i.e. the discharge/charge rate). Furthermore, the capacity of a battery is normally given in A $\cdot h$ (ampere hour), which also depends on the discharge rate. In addition, the state of charge or the depth of discharge of a battery are normally given as a percentage of the battery capacity which, as stated, depends on the discharge rate.

The UPMSat-2 mission battery testing was performed at the Thermal VAcuum Chamber (TVAC) of the IDR/UPM Institute, in December 2017 (see figure 1). As expected, very high efficiency levels (between $97.5 \%$ and $99 \%$ ) were measured during the discharging and charging processes. After this testing, our research group decided to study the energy discharge level as the primary variable to analyze Li-ion battery performance. The UPMSat-2 battery is a space-qualified $18 \mathrm{~A}$. h Li-ion battery manufactured by SAFT Batteries (more information on the mission can be found in [5-7]).

The present work is organized as follows. In section 2, the model proposed is described, together with the testing setup developed to obtain experimental results related to $\mathrm{Li}$-ion battery discharging/charging processes. The results are discussed in section 3 , and the conclusions are summarized in section 4.

\section{Battery modeling and experimental set-up}

\subsection{Battery modeling}

As previously mentioned, the core of the present work assumes that the efficiency of a Li-ion battery is high enough to consider zero energy losses. Taking this fact into account, the energy discharge level, $\phi$, of a Li-ion battery has been defined as:

$$
\phi=\phi_{0}+\int_{t_{0}}^{t} E^{\mathrm{d}} I \mathrm{~d} t=\phi_{0}+\int_{t_{0}}^{t}\left(V I+R_{\mathrm{d}} I^{2}\right) \mathrm{d} t,
$$

for the discharging process, whereas for the charging process was defined as:

$$
\phi=\phi_{0}-\int_{t_{0}}^{t} E^{\mathfrak{c}} I \mathrm{~d} t=\phi_{0}-\int_{t_{0}}^{t}\left(V I-R_{\mathrm{c}} I^{2}\right) \mathrm{d} t,
$$

where $E^{\mathrm{c}}$ and $E^{\mathrm{d}}$ are the internal voltage level of the battery during charging and discharging, respectively, $I$ is the output/ input current, $R_{\mathrm{d}}$ is the internal resistor during the discharging procedure, $R_{\mathrm{c}}$ is the internal resistor during the charging procedure and $\phi_{0}$ is the battery level of discharge at instant 


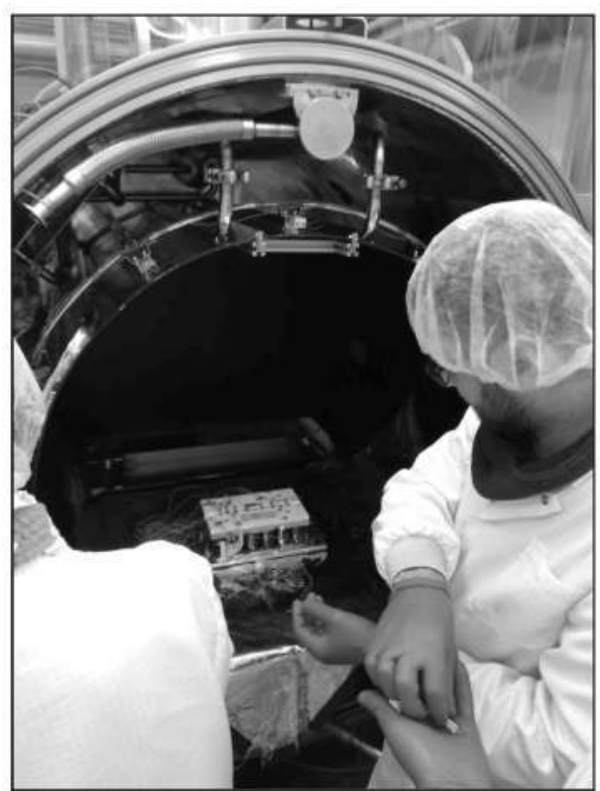

Figure 1. UPMSat-2 battery testing at the IDR/UPM Institute TVAC.
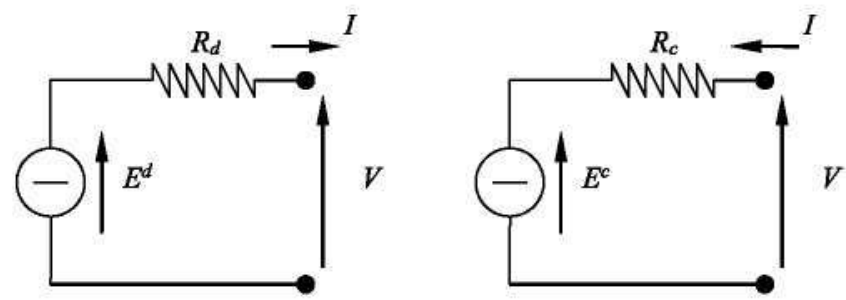

Figure 2. Equivalent circuit models for a Li-ion battery during discharging (left) and charging (right) processes. See also equations (3) and (4).

$t_{0}$. The two equivalent circuit models, for the discharging and charging processes, are shown in figure 2.

The output voltage from each process can then be expressed as:

$$
\begin{aligned}
& V(\phi, I)=E^{\mathrm{d}}-R_{\mathrm{d}} I, \\
& V(\phi, I)=E^{\mathrm{c}}+R_{\mathrm{c}} I,
\end{aligned}
$$

with the internal battery voltages being expressed in relation to the discharge energy, $\phi$, and a group of constants/parameters to be extracted:

$$
\begin{aligned}
& E^{\mathrm{d}}=f\left(\phi, E_{0}^{\mathrm{d}}, E_{1}^{\mathrm{d}}, E_{2}^{\mathrm{d}} \ldots\right), \\
& E^{c}=g\left(\phi, E_{0}^{\mathrm{c}}, E_{1}^{\mathrm{c}}, E_{2}^{\mathrm{c}} \ldots\right) .
\end{aligned}
$$

In principle, coefficients $E_{i}^{\mathrm{d}}$ and $E_{i}^{\mathrm{c}}$ are not dependent on the current $I$ (this statement is discussed in section 3 ).

Once the discharging and charging models had been proposed, a complete battery model that takes both into account was derived for the static performance (static performance refers to discharging or charging operations at constant current), see figure 3 . This model is similar to the hysteresis model proposed by Bangaru et al [8].



Figure 3. Li-ion battery model proposed for static charging and discharging processes.

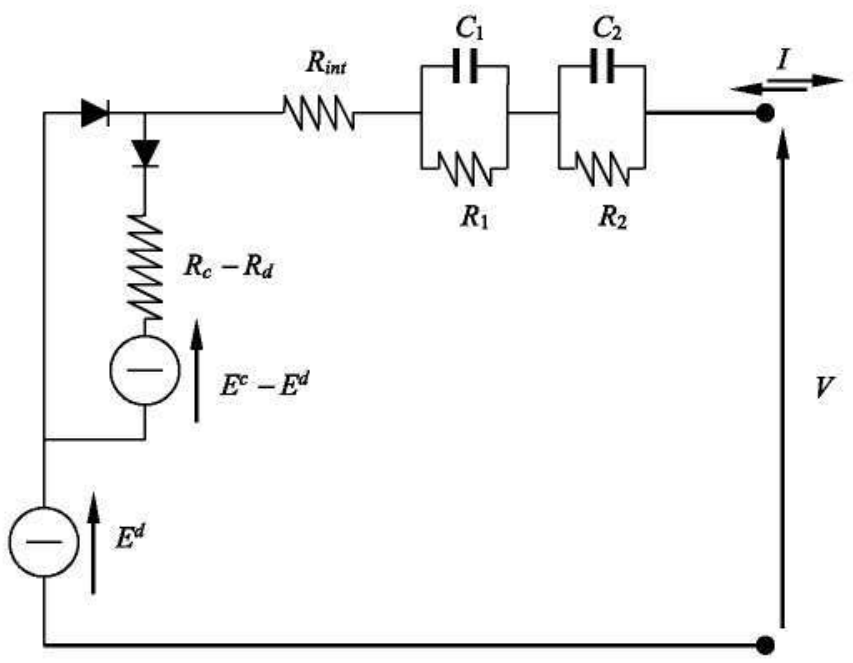

Figure 4. Complete Li-ion battery model proposed, for static and dynamic performance.

Finally, the non-static or dynamic performance had been taken into account, by adding two pairs of resistor-capacitor parallel elements connected in series to the static models, see figure 4. Obviously, in this case:

$$
R_{\mathrm{d}}=R_{\text {int }}+R_{1}+R_{2} .
$$

\subsection{Experimental set-up and testing procedure}

A $17.2 \mathrm{Li}$-ion battery was used to test and calibrate the proposed model and analyze its performance. This battery is based on Samsung INR 18650-25R cells [9], comprising six series (each one of six cells) parallel connected. In figure 5, the testing set-up of the battery is shown. A Mayuno M9812 DC Electronic Load controlled by Mayuno M9711 software, and an ISO-TECH IPS3303 Bench Power Supply were used to carry out all the tests.

Two discharging/charging processes were initially programmed, at 0.5 and $3.5 \mathrm{~A}$. After that, four more discharging/ 


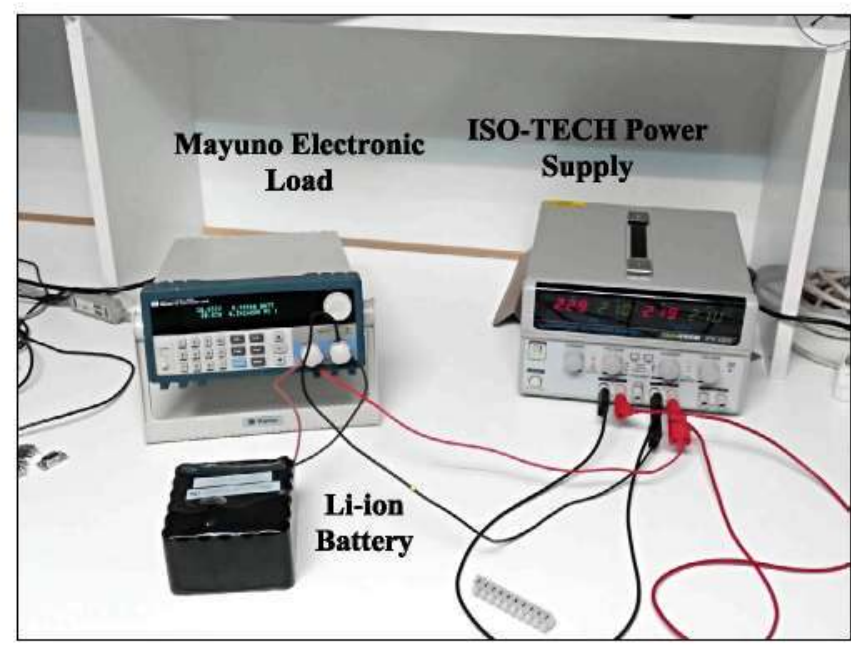

Figure 5. Testing set-up for the $\mathrm{Li}$-ion batteries.
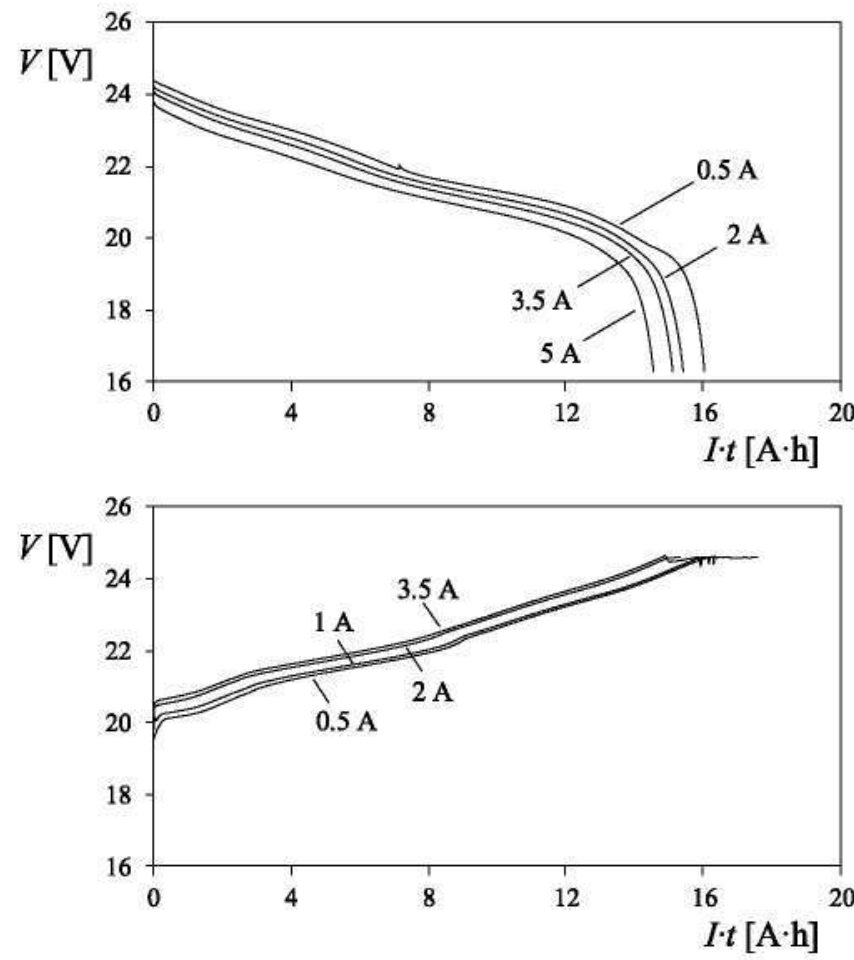

Figure 6. Discharging (top) and charging (bottom) processes performed on the Li-ion battery tested.

charging processes were carried out at 1 and $2.5 \mathrm{~A}$ (charge), and 2 and $5 \mathrm{~A}$ (discharge). The reason for this asymmetry lies in the purpose of the present work, to develop a battery model for small satellites $(50 \mathrm{~kg})$ in which the discharge rates are larger than the charge rates. This is because the power consumption is periodically boosted due to communication with Ground Control (and also the charge rate might be limited due to low temperatures-e.g. after an eclipse-).

The discharging process measurements were started from the full-charge state and stopped at $V=16.3 \mathrm{~V}$ (that implies a $2.7 \mathrm{~V}$ limitation per cell plus $0.1 \mathrm{~V}$ safety margin to take
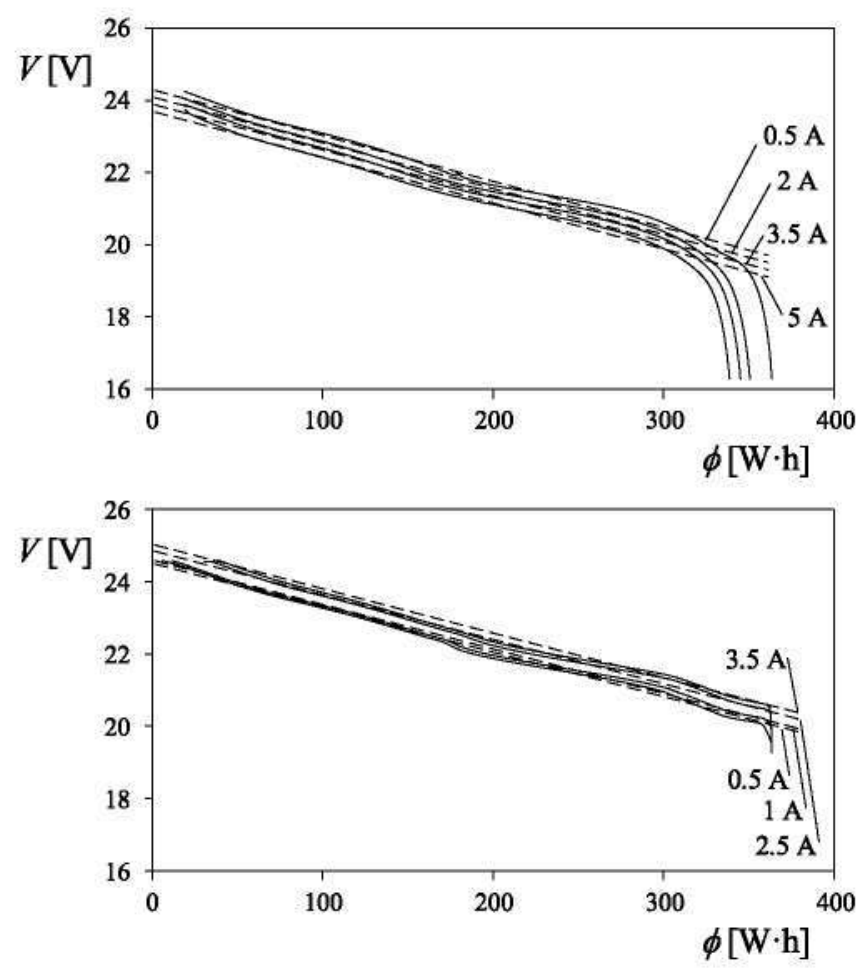

Figure 7. Discharging (top) and charging (bottom) voltages measured at different rates, expressed in relation to the discharged energy rate, $\phi$. Fittings of the equivalent circuit model (equations (3) and (4)) with the internal voltage linear model (Model 1; equations (8) and (9)) have also been included as dashed lines. See also table 1 .

into account cell unbalance). On the other hand, the charging process measurements were started from the remaining state after a discharging process, stopping at $V=24.6 \mathrm{~V}(4.1 \mathrm{~V}$ per cell). Then, the charging process was restarted at a reduced rate until the $24.6 \mathrm{~V}$ limitation. This process was repeated to progressively reduce the charge rate till $I=100 \mathrm{~mA}$, which was the last charge rate.

\section{Results}

In figure 6 , the evolution of the battery output voltage, $V$, during the discharging/charging processes is shown in relation to the current discharge/charge level, I.t, expressed in A - h. In this figure, it can be observed that the curves related to the discharging processes present a linear behavior initially, followed by a sudden decay that might fit an exponential function. On the other hand, the charging processes clearly show a linear behavior.

From the linear part of these curves, a first estimation of the internal resistors, $R_{\mathrm{d}}$ and $R_{\mathrm{c}}$, can be obtained. Selecting three different discharge/charge rates $(I \cdot t=4.17,6.94$ and $9.72 \mathrm{~A} \cdot \mathrm{h}$ for the discharging processes; $I \cdot t=2.78,6.94$ and $9.72 \mathrm{~A} \cdot \mathrm{h}$ for the charging processes), and taking into account:

$$
\Delta V=R_{\mathrm{d} ; \mathrm{c}} \Delta I,
$$


Table 1. Coefficients of the equivalent circuit model (equations (3) and (4)) with the internal voltage linear model (Model 1: equations (8) and (9)). obtained in the three iterations carried out (It. 1. It. 2 and It. 3), starting from an initial state (It. 0).

\begin{tabular}{llccc}
\hline Coefficient & It. 0 & It. 1 & It. 2 & It. 3 \\
\hline$R_{\mathrm{d}}(\Omega)$ & 0.14718 & 0.13316 & 0.13316 & 0.13316 \\
$E_{0}^{\mathrm{d}}(\mathrm{V})$ & - & 24.6 & 24.384 & 24.384 \\
$E_{1}^{\mathrm{d}}\left(\mathrm{V} \cdot \mathrm{W}^{-1} \cdot \mathrm{h}^{-1}\right)$ & - & $-3.6 \cdot 10^{-3}$ & $-1.271 \cdot 10^{-2}$ & $-1.271 \cdot 10^{-2}$ \\
$R_{\mathrm{c}}(\Omega)$ & 0.15913 & 0.17547 & 0.17547 & 0.17547 \\
$E_{0}^{\mathrm{c}}(\mathrm{V})$ & - & 24.6 & 24.446 & 24.446 \\
$E_{1}^{\mathrm{c}}\left(\mathrm{V} \cdot \mathrm{W}^{-1} \cdot \mathrm{h}^{-1}\right)$ & - & $-3.6 \cdot 10^{-3}$ & $-1.231 \cdot 10^{-2}$ & $-1.231 \cdot 10^{-2}$ \\
\hline
\end{tabular}
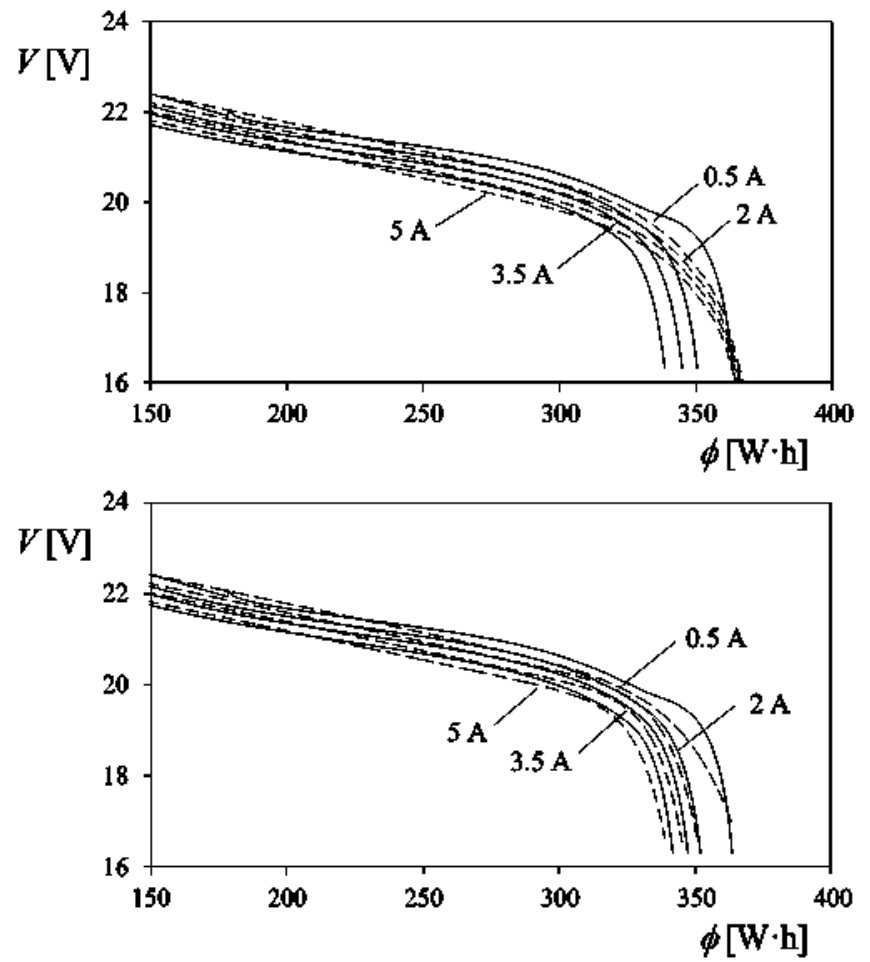

Figure 8. Fittings (dashed lines) of the discharging equivalent circuit model (equation (3)) to the testing results. Battery internal voltage is modelled with both linear and exponential terms (equation (11)). the constants of the exponential term being constant (top) and dependent on the current rate (bottom: see also table 2).

the following mean and initial estimations for the resistors were obtained: $R_{\mathrm{d}}=0.1472 \Omega(\sigma=0.028 \Omega) ; R_{\mathrm{c}}=0.1591 \Omega$ $(\sigma=0.053 \Omega)$.

Based on these resistor values, it is then possible to calculate the energy discharge level, $\phi$, associated to the discharging and charging processes (equations (1) and (2)), in order to plot again the battery voltage evolution during the discharging/charging processes as a function of this new variable, see figure 7 . Then, if only the linear part of the curves is considered, a first-order modeling of the battery internal voltages can be fitted to the curves:

$$
\begin{aligned}
& E^{\mathrm{d}}(\phi)=E_{0}^{\mathrm{d}}+E_{1}^{\mathrm{d}} \phi, \\
& E^{c}(\phi)=E_{0}^{c}+E_{1}^{\mathrm{c}} \phi,
\end{aligned}
$$

with the constants $E_{0}^{\mathrm{d}}, E_{1}^{\mathrm{d}}, E_{0}^{\mathrm{c}}$ and $E_{1}^{\mathrm{c}}$ therefore being extracted, together with new values for resistors, $R_{\mathrm{d}}$ and $R_{\mathrm{c}}$, that lead
Table 2. Coefficients of the internal voltage discharging model (equation (11)) exponential term, in relation to the discharging current.

\begin{tabular}{lllll}
\hline & \multicolumn{4}{c}{ Discharging current } \\
\cline { 2 - 5 } Coefficient & $0.5 \mathrm{~A}$ & $2 \mathrm{~A}$ & $3.5 \mathrm{~A}$ & $5 \mathrm{~A}$ \\
\hline$E_{2}^{\mathrm{d}}(\mathrm{V})$ & $-5.600 \cdot 10^{-9}$ & $-3.592 \cdot 10^{-15}$ & $-8.042 \cdot 10^{-17}$ & -3.149 \\
& & & & $10^{-16}$ \\
$E_{?}^{\mathrm{d}}$ & $5.508 \cdot 10^{-2}$ & $9.803 \cdot 10^{-2}$ & $1.106 \cdot 10^{-1}$ & 1.084 \\
$\left(\mathrm{~W}^{-1} \cdot \mathrm{h}^{-1}\right)$ & & & & $10^{-1}$ \\
\hline
\end{tabular}
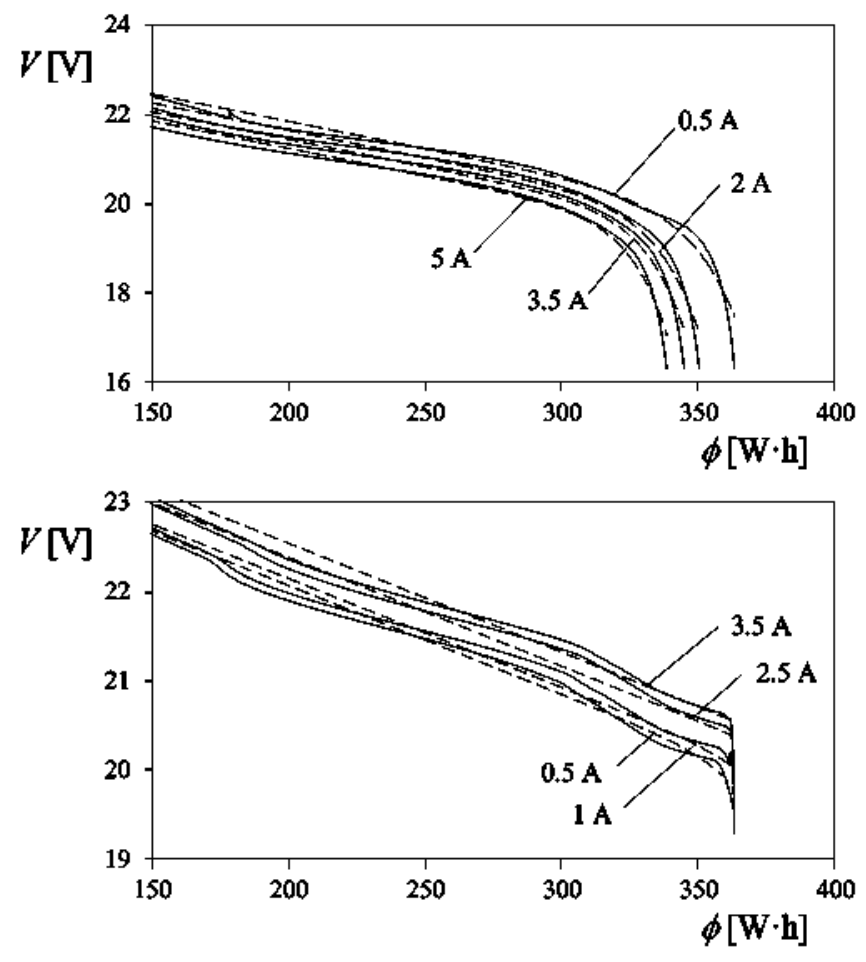

Figure 9. Discharging (top) and charging (bottom) voltages measured at different rates, expressed in relation to the discharged energy rate. 4 . Fittings of the equivalent circuit model (equations (3) and (4)) with the internal voltage linear model (Model 2: equations (12) and (13)) have also been included as dashed lines. See also table 3.

to a new, more accurate calculation of the energy discharge level, $\phi$. This process can be repeated in order to obtain a more accurate approach to the linear behavior of the battery (see figure 7). In table 1, the values obtained are included in relation to the iteration carried out. Finally, it should also be 
Table 3. Coefficients of the equivalent circuit model (equations (3) and (4)) with the internal voltage modelled with equations (12) and (13) (Model 2). Results from the three iterations carried out (It. 1, It. 2 and It. 3), starting from an initial state (It. 0).

\begin{tabular}{|c|c|c|c|c|}
\hline Coefficient & It. 0 & It. 1 & It. 2 & It. 3 \\
\hline$R_{\mathrm{d}}(\Omega)$ & 0.13316 & 0.13433 & 0.13433 & 0.13433 \\
\hline$E_{0}^{\mathrm{d}}(\mathrm{V})$ & 24.384 & 24.369 & 24.369 & 24.369 \\
\hline$E_{1}^{\mathrm{d}}\left(\mathrm{V} \cdot \mathrm{W}^{-1} \cdot \mathrm{h}^{-1}\right)$ & $-1.0 \cdot 10^{-2}$ & $-1.2277 \cdot 10^{-2}$ & $-1.2276 \cdot 10^{-2}$ & $-1.2276 \cdot 10^{-2}$ \\
\hline$E_{2,0}^{\mathrm{d}}(\mathrm{V})$ & $-5.0 \cdot 10^{-9}$ & $-1.0621 \cdot 10^{-9}$ & $-1.0619 \cdot 10^{-9}$ & $-1.0617 \cdot 10^{-9}$ \\
\hline$E_{2,1}^{\mathrm{d}}(\Omega)$ & $-1.0 \cdot 10^{-8}$ & $-4.4697 \cdot 10^{-10}$ & $-4.4689 \cdot 10^{-10}$ & $-4.468 \cdot 10^{-10}$ \\
\hline$E_{2,2}^{\mathrm{d}}\left(\Omega \cdot \mathrm{A}^{-1}\right)$ & $-1.0 \cdot 10^{-8}$ & $-4.785 \cdot 10^{-11}$ & $-4.7839 \cdot 10^{-11}$ & $-4.783 \cdot 10^{-11}$ \\
\hline$E_{3,0}^{\mathrm{d}}\left(\mathrm{W}^{-1} \cdot \mathrm{h}^{-1}\right)$ & $5.0 \cdot 10^{-2}$ & $5.8079 \cdot 10^{-2}$ & $5.8147 \cdot 10^{-2}$ & $5.8151 \cdot 10^{-2}$ \\
\hline$E_{3,1}^{\mathrm{d}}\left(\mathrm{W}^{-1} \cdot \mathrm{h}^{-1} \cdot \mathrm{A}^{-1}\right)$ & $-1.0 \cdot 10^{-3}$ & $-3.3582 \cdot 10^{-3}$ & $-3.3609 \cdot 10^{-3}$ & $-3.3599 \cdot 10^{-3}$ \\
\hline$R_{\mathrm{c}}(\Omega)$ & 0.17547 & 0.1571 & 0.15724 & 0.15724 \\
\hline$E_{0}^{\mathrm{c}}(\mathrm{V})$ & 24.446 & 24.421 & 24.421 & 24.421 \\
\hline$E_{1}^{\mathrm{c}}\left(\mathrm{V} \cdot \mathrm{W}^{-1} \cdot \mathrm{h}^{-1}\right)$ & $-1.0 \cdot 10^{-2}$ & $-1.2169 \cdot 10^{-2}$ & $-1.2171 \cdot 10^{-2}$ & $-1.2171 \cdot 10^{-2}$ \\
\hline$E_{2}^{\mathrm{c}}(\mathrm{V})$ & $-1.0 \cdot 10^{-8}$ & $-9.006 \cdot 10^{-14}$ & $-2.6699 \cdot 10^{-14}$ & $-2.6493 \cdot 10^{-14}$ \\
\hline$E_{3,0}^{\mathrm{c}}\left(\mathrm{W}^{-1} \cdot \mathrm{h}^{-1}\right)$ & $5.0 \cdot 10^{-2}$ & $8.1032 \cdot 10^{-2}$ & $8.4359 \cdot 10^{-2}$ & $8.4402 \cdot 10^{-2}$ \\
\hline$E_{3,1}^{\mathrm{c}}\left(\mathrm{W}^{-1} \cdot \mathrm{h}^{-1} \cdot \mathrm{A}^{-1}\right)$ & $-1.0 \cdot 10^{-3}$ & $-3.9841 \cdot 10^{-3}$ & $-3.8999 \cdot 10^{-3}$ & $-3.8938 \cdot 10^{-3}$ \\
\hline
\end{tabular}

mentioned that the fittings were carried out for the linear sections of the curves, that is, $\phi \in[50,260] \mathrm{W} \cdot \mathrm{h}$ in the case of the discharging processes, and for $\phi \in[50,350] \mathrm{W} \cdot \mathrm{h}$ in the case of the charging processes. This linear model of the discharging and charging processes is called hereinafter Model 1.

A more complex model was analyzed for the internal battery voltage, considering an exponential term for the discharging process:

$$
E^{\mathrm{d}}(\phi)=E_{0}^{\mathrm{d}}+E_{1}^{\mathrm{d}} \phi+E_{2}^{\mathrm{d}} \exp \left(E_{3}^{\mathrm{d}} \phi\right) .
$$

In this model, the values of constants $E_{0}^{\mathrm{d}}, E_{1}^{\mathrm{d}}$ and $R_{\mathrm{d}}$ are preserved from Model 1. As can be observed in figure 8 (top), this model does not represent well enough the behavior of the discharging processes. However, if different constants $E_{2}^{\mathrm{d}}$ and $E_{3}^{\mathrm{d}}$ are considered for each different current, the model fits the experimental results much better (see figure 8 (bottom)). In table 2, the coefficients $E_{2}^{\mathrm{d}}$ and $E_{3}^{\mathrm{d}}$ obtained for all currents are included.

Bearing in mind the effect of the current on the coefficients, the following model (Model 2) was finally proposed for the internal voltage during the discharging/charging processes:

$$
\begin{aligned}
& E^{\mathrm{d}}(\phi)=E_{0}^{\mathrm{d}}+E_{1}^{\mathrm{d}} \phi \\
& \quad+\left(E_{2,0}^{\mathrm{d}}+E_{2,1}^{\mathrm{d}} I+E_{2,2}^{\mathrm{d}} I^{2}\right) \exp \left[\left(E_{3,0}^{\mathrm{d}}+E_{3,1}^{\mathrm{d}} I\right) \phi\right], \\
& E^{\mathrm{c}}(\phi)=E_{0}^{\mathrm{c}}-E_{1}^{\mathrm{c}} \phi-E_{2}^{\mathrm{c}} \exp \left[\left(E_{3,0}^{\mathrm{c}}+E_{3,1}^{\mathrm{c}} I\right) \phi\right] .
\end{aligned}
$$

In figure 9 , the fittings of the aforementioned discharging/charging models (equations (3) and (4)), bearing in mind the above equations, are shown. In table 3 , the coefficients of equations (12) and (13) are included in relation to the iteration carried out during the fitting process. As was done in the case of Model 1, new values of the internal resistors were obtained in each iteration, the energy discharge level, $\phi$, being consequently recalculated.

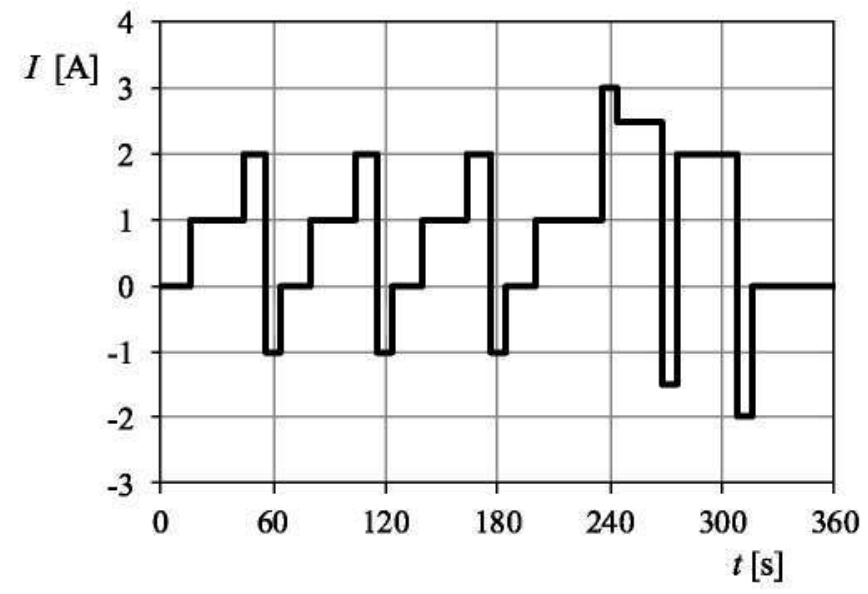

Figure 10. 20-step dynamic discharging/charging period of $360 \mathrm{~s}$ programmed to measure the dynamic battery performance. This cycle is similar to the one included in the USABC battery test procedures manual [10].

A discharging process at $2 \mathrm{~A}$ rate, combined with 20-step dynamic discharging/charging periods of 360 s each hour was programmed to obtain data to adjust the complete model from figure 4 . In figure 10, the discharging current during these dynamic periods is plotted. Obviously, the current has negative values in the charging steps. In figure 11 , the battery voltage during this discharging process is shown. The complete model for the battery (figure 4) was then fitted to this data, the values associated to the internal resistor and the two resistor-capacitor pairs being extracted $\left(R_{\text {int }}=0.07707 \Omega ; R_{1}=0.03777 \Omega\right.$; $\left.R_{2}=0.01949 \Omega ; C_{1}=1100 \mathrm{~F} ; C_{2}=950 \mathrm{~F}\right)$.

The model was finally programmed in a Matlab/Simulink environment, and was tested with the same discharge/charge rate used to measure the dynamic battery performance. The results are included in figure 11 , in which the model performance and the battery performance can be compared. The comparison between the model and the battery performance during the second 20-step dynamic discharging/charging period 

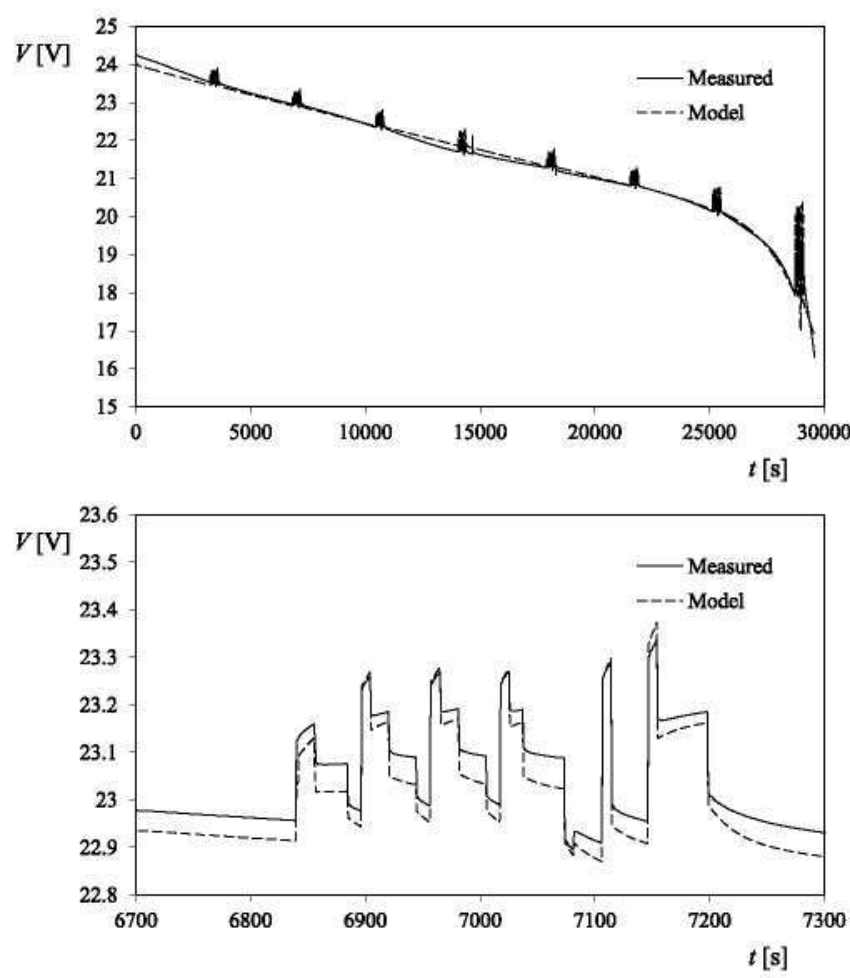

Figure 11. (Top) discharging process of the tested Li-ion at $2 \mathrm{~A}$ rate, combined with 20-step dynamic discharging/charging periods of 360 s each hour (see figure 10). Results of the proposed model have also been included (dashed line). Results from the second 20-step dynamic discharging/charging period have been plotted in detail, in the bottom graph.

is also plotted in the bottom graph of the figure, in order to compare the behavior during sudden changes of battery discharge/charge rate. In this graph, one can observe the good performance of the model, with deviations of $\Delta V<0.1 \mathrm{~V}$ in relation to the measured performance of the Li-ion battery tested.

\section{Conclusions}

A new model for Li-ion battery performance based on the energy discharge level has been proposed. Bearing in mind that the present work is an early communication and more research should be carried out, it can be said that the results from the proposed model reproduce the test results (discharging/charging processes) of a $17.2 \mathrm{~A} \cdot \mathrm{h}$ Li-ion battery. Finally, it should also be mentioned that, although temperature changes or the number of discharging/charging cycles have not been taken into account in this work, these variables will be analyzed in future research campaigns to improve the proposed model.

\section{Acknowledgments}

The authors are indebted to Prof Ángel Sanz-Andrés for his encouraging support regarding the research program on battery performance at IDR/UPM. Furthermore, the authors would like to express their gratitude to the IDR/UPM staff and colleagues for the kind help regarding the testing campaigns carried out to obtain the results described in this work.

\section{ORCID iDs}

Ángel Porras-Hermoso (C) https://orcid.org/0000-0002-35760603

Santiago Pindado (O https://orcid.org/0000-0003-2073-8275

Javier Cubas @ https://orcid.org/0000-0001-9787-3796

\section{References}

[1] Newman J, Thomas K E, Hafezi H and Wheeler D R 2003 Modeling of lithium-ion batteries J. Power Sources 119-21 838-43

[2] He H, Xiong R, Guo H and Li S 2012 Comparison study on the battery models used for the energy management of batteries in electric vehicles Energy Convers. Manag. $64113-21$

[3] Mousavi G S M and Nikdel M 2014 Various battery models for various simulation studies and applications Renew. Sustain. Energy Rev. 32 477-85

[4] Fotouhi A, Auger D J, Propp K, Longo S and Wild M 2016 A review on electric vehicle battery modelling: from lithiumion toward lithium-sulphur Renew. Sustain. Energy Rev. $561008-21$

[5] Pindado S et al 2017 The UPMSat-2 satellite: an academic project within aerospace engineering education Athens: ATINER'S Conf. Paper Series, No: ENGEDU2017-2333 (Athens: Athens Institute for Education and Research. ATINER) pp 1-28 (http://www.atiner.gr/papers/ ENGEDU2017-2333.pdf)

[6] Roibás-Millán E, Alonso-Moragón A, Jiménez-Mateos A and Pindado S 2017 Testing solar panels for small-size satellites: the UPMSAT-2 mission Meas. Sci. Technol. 28115801

[7] Pindado S, Cubas J, Roibás-Millán E and Sorribes-Palmer F 2018 Project-based learning applied to spacecraft power systems: a long-term engineering and educational program at UPM University CEAS Sp. J. $10307-23$

[8] Bangaru S, Alugonda R and Palacharla P 2013 Modeling and simulation of lithium-ion battery with hysteresis for industrial applications 2013 Int. Conf. on Energy Efficient Technologies for Sustainability, ICEETS 2013 pp 771-5

[9] Kang H and Rim M 2012 Samsung INR18650-29E lithium-ion rechargeable cell. Specifications of product. SAMSUNG SDI Co., Ltd. Energy Business Division

[10] Duong T Q 2000 USABC and PNGV test procedures J. Power Sources $89244-8$ 